\title{
Assessing the Legal Personality of Sexbots in the Light of Human Rights
}

'The real question is, when will we draft an artificial intelligence bill of rights? What will that consist of? And who will get to decide that?' - Gray Scott ${ }^{1}$

\begin{abstract}
Sexbots have been the subject of much prurient curiosity for all of the adult population. The scepticism about the extent of human interaction in the future has created ambiguity about the prospects of the flesh trade industry all over the world. The evolution of sexbots from animatronic models to sentient beings capable of decisionmaking ability would pose a fundamental question about their impact on buman rights and the obstacles it would create for the people employed in this sector. The ethico-legal constraints about their replacements as sex workers for utilitarian purposes evaluate the boundaries of acceptable sexual practices. With the advent of artificial intelligence in robotics, these customizable simulacra capable of human affection explore the pragmatic question of their legal personality. This paper analyzes the intersectionality of artificial intelligence and robotics in the light of etbical limits and legal implications on buman rights. It imposes a duty on humans to address the permissible limits of customizability and the sufficiency of the existing legal framework to minimize the sufferings of these sentient beings. The complexities involved in the controversial facet of buman-robot relationship entail us to gange upon the jurisprudential aspects of the rights and legal personality of these robots.
\end{abstract}

\section{Introduction}

The unprecedented situation of the COVID-19 crises has caused us to debate the future operations of businesses whilst limiting the interaction among humans. The advent and accessibility of technology have facilitated the transition to the telework culture which has reduced the impact of the economic upheaval without affecting the efficiency of the employees. This advancement of robotics and artificial intelligence has even transcended the fields of an ordinary employment and has further integrated robots into

\footnotetext{
* Arushi Gupta is a final year L.L.B. student at Indian Law Society Law College, Pune, India. She has graduated in B.A. (Hons) Business Economics from University of Delhi. She can be reached at arushigupta1928@gmail.com.

1 Futurist, Emerging Technology Expert.
} 
the fabric of everyday human life through Roomba(s), and Amazon echo devices which clean our houses and, articulately respond to our commands. Similarly, the conceptually implausible idea of sex robots (herein after referred to as sexbots) percolating into the sexual sphere has now become a commercially viable business idea for many.

The existence of sexbots has created an obligation on the lawmakers and scholars to address the questions related to their legal personality and formulate a legal framework to inculcate the concept of robot-human relationships (also known as digisexuality). The characterization of the relationship between humans and inanimate robots would depend on the consensual nature of the intimate acts involved. The impact of these relationships remains highly ambiguous and requires an examination of the cultural background and its acceptance in jurisdictions all across the world.

Recently, these conscious and sexual couplings have been a frequent subject in literature and fantasy cinema and are subject to condemnation as they are considered unnatural and a taboo amongst people of various cultures. The emotional attachment and the sexual affinity that people are experiencing towards the robots are some of the most complex and certainly the most contentious aspect of human-robot relationships ${ }^{2}$.

\section{History}

Sexbots are a rapidly emerging technology, engineered for sexual stimulation and are likely to have a profound effect upon the future of human sexual relations. Although sex robots are a fairly new phenomenon, their remote intimacy man-made variants have been in existence since thousands of years ${ }^{3}$.

During the 17th Century, during long voyages sailors would take with them archetype of the inflatable doll resembling a human female, fashioned out of fabric attached to bamboo poles for companionship. Prior to the $20^{\text {th }}$ century very little proof exists of these creations mainly because of the materials used to create them.

The sex dolls advertised in the 1960s were available for purchase through mail, were inflatable with air and consisted of necessary orifices for penetration. However, they were not sustainable for long use because of the material used for their formation. Later more durable materials such as latex and silicon were used for their manufacturing ${ }^{4}$.

The present-day models of the sexbots are an amalgamation of robotics and artificial intelligence. These complex models are currently still in their primitive stage but are evolving very rapidly and thus, pose a plethora of problems with respect to the lack of

2 Benjamin Hass, 'Chinese man marriesthe robot he built himself', The Guardian, 4 April 2017, available at https://www.theguardian.com/world/2017/apr/04/chinese-man-marries-robot-builthimself\#: :text=A $\% 20$ Chinese $\% 20$ artificial $\% 20$ intelligence $\% 20$ engineer,friend $\% 20$ told $\% 20$ Qianjiang\%20Evening\%20News., accessed on 20 July 2020.

3 Scott Dewing, 'The rise of the Sexbots', Jeffersons Public Radio, 2019, available at https://www.ijpr.org/ science-technology/2019-03-01/the-rise-of-the-sexbots, accessed on 20 July 2020.

4 Anthony Ferguson, The Sex Doll: A History, McFarland \& Company, US, 2010, p. 31. 
regulations governing them ${ }^{5}$.

\section{Cinematic Representation}

Sex robots have been represented in cinema since early $21^{\text {st }}$ century which more lately have focused on the awareness of their artificial existence. They have been depicted to provide solace to the lonely, socially awkward humans seeking companionship. The movie Her, focuses on the ability of humans and artificial intelligence to form emotional bonds with one another solely by communicating. This same artificial intelligence is expanded into the robots in Ex Machina and Blade Runner $2049^{6}$.

These movies depict the ease of communicating with an artificial entity and their ability to respond in a manner that is pleasant and welcomed by their human counterpart which ensures that a connection can be formed between the two. This relationship can be embodied in real life with availability of sexbots with emotional capabilities of reciprocating emotions that humans otherwise seek.

\section{Legal Personality}

The existence of sentient beings requires an evaluation of the status of their legal personality. With the grant of citizenship to Sophia, a humanoid robot developed by Hanson Robotics this concept does not seem outlandish or speculative. Thus, the jurisprudential aspect of legal personality which recognizes two kinds of legal personalities, natural and artificial comes into play. A subject of artificial legal personality constitutes entities having rights and duties. Salmond defines a person as, 'any being to whom the law regards as capable of rights or duties. Any being that is so capable, is a person whether a human being or not and nothing that is not so capable is a person even though he be a $\operatorname{man}^{7}$.'

The granting of legal personality to the robots is based on drawing analogies with the artificial legal corporations, idols and animals ${ }^{8}$. Salmond regards animals not as legal persons but mere objects of legal rights and duties and not as their subjects and thus, no legal personality is granted to them. Under most circumstances, the owner of the animal is held vicariously liable in case of any damage caused by the pet. However, the grant of legal personality to new beings is based on how the present population would respond to the changes and the effect on the legal framework by recognizing their rights and liabilities?.

\footnotetext{
5 Malini Goyal, 'Quantum Leap: The rise of sexbots and artificial human beings', The Economic Times, 28 December 2019, available at https://economictimes.indiatimes.com/tech/hardware/quantum-leap-the-riseof-sexbots-and-artificial-human-beings/articleshow/73010869.cms?from=mdr, accessed on 21 July 2020.

'Computer Love: Sexbots in Cinema', Boshemia, 12 February 2019, available at https://www. boshemiamagazine.com/blog/2019/02/12/computer-love-sexbots-in-cinema, accessed on 24 July 2020.

P.J. Fitzgerlad, Salmond on Jurisprudence, Sweet \& Maxwell, 12 ${ }^{\text {th }}$ edition, 2021, p. 299.

$8 \quad$ S.M. Solaiman, 'Legal personality of robots, corporations, idols and chimpanzees: a quest for legitimacy', Artificial Intelligence and Law, 25(2).

9 Roman Dremliuga, Pavel Kuznetcov \& Alexey Yu. Mamychev, 'Criteria for Recognition of AI as a Legal
} 
The recognition of robots as sentient beings and a partner in a marriage requires sui generis legislations which would grant them artificial legal personality. The future customizations of the robots not only in appearance but also in their ability to mimic human emotions according to the need and utility of the consumer gives rise to a plethora of ethico-legal complexities including the permissible limits to customizations. Acknowledging the legal personality of the sexbots would also bring them under the umbrella of the international human rights thereby, preventing their exploitation. Their awareness and capacity to reciprocate human emotions imply that they cannot be merely categorized as just objects and cannot be customized to be subjected to human mistreatment.

\section{International Legislations}

The European Union in a draft resolution after addressing the indispensable nature of robots in the daily lives of humans explored the possibility of the robots enjoying the same rights as their human creator with the purpose of enabling their use without any physical or psychological harm. The draft also acknowledged the lack of efficient legislations to regulate these new types of beings capable of making autonomous decisions and request for an amendment in the international framework to set regulatory standards for their global governance ${ }^{10}$.

In the United States, the Curbing Realistic Exploitative Electronic Pedophilic Robots (CREEPER) Act ${ }^{11}$ was introduced in the U.S House of Representatives to curb the growing problem of pedophilia. The purpose of this bill was to ban and criminalize the interstate commerce of anatomically correct dolls that resembled minors as it is believed that the ease of buying such products would desensitize, legitimize and reinforce such pedophilic behavior.

Their customizations include suffering as a part of an experience for the consumer or the buyer and the nature of duty that is owed to them by their engineer to protect their interests and mitigate their sufferings would also come under scrutiny. These possibilities of their legal recognition and further penetration into the market come with their own set of challenges and their possible impact on the future of sex trafficking and sex workers.

\section{Impact on Sex Workers}

The sexbots are not likely to enter the large-scale market in the near future because of their expensive purchasing costs ranging from $\$ 5000$ - $\$ 15000^{12}$. However, with

Person', Journal of Politics and Law, volume 12:3, 2019.

10 Mady Delvaux, 'Draft Report with recommendations to the Commission on Civil Law Rules on Robotics (2015/2103(INL))', European Parliament, 2016.

11 Curbing Realistic Exploitative Electronic Pedophilic Robots (CREEPER) Act, 2017.

12 Bruce Y. Lee, 'In case you are wondering, Sex with Robots May Not Be Healthy', Forbes, 5 June 2018, available at https://www.forbes.com/sites/brucelee/2018/06/05/in-case-you-are-wondering-sex-with- 
economies of scale, this cost is eventually likely to come down. The possibility of sexbots as sex workers also explores the idea of them replacing humans as sex workers completely, thereby, eliminating this social evil where trafficked women are forced to participate. That is, however, only an optimist's view.

The brothels in many parts of the world have already started employing them in what is considered the world's oldest profession ${ }^{13}$. This change has been unwelcomed by the sex workers who claim that this would promote unhealthy behavior which could prove to be dangerous for real women as men get accustomed to a partner that is unresponsive during any sexual activity ${ }^{14}$.

The practice of renting these dolls has been active in Japan since a long time and has now gained traction in other parts of the world. In Canada, the same service has recently opened in Vancouver with the business license of operating as an adult novelty item rental agency ${ }^{15}$. Their claim is that the business is highly similar to any business providing sex toys.

Although, no study exists to conclude a causal relationship between the two, such acts with a doll are likely to legitimize violent behavior which might cause an increase in the abusive relationship towards women. These trends are also likely to shift a large number of women especially from poor countries towards extreme poverty and may cause them to agree to participate in activities for a lower price which they would not permit in absence of competition from a robot.

\section{Consent}

The social robots supplied as intimate companions will further expand the questions pertaining to ethical and legal issues. If self-awareness and decision-making capabilities are to be designed into the robots will they also have the ability to consent or refuse to acts? In relationships, intimacy significantly depends on the mutuality and reciprocation. The ethical aspects and the advocates of this field believe in accepting all aspects of a consensual adult relationship which is not based on coercion, exploitation and abuse, therefore, the aspect of pain in robotics requires a cautious consideration. The future fields of inquiry also have to consider the aspect of autonomy in the robots and the limits on the autonomy of the bots that humans are justified in designing.

There has also been a change in how consent is viewed and a debate on different models of consent has also come within the traditional dichotomy of the 'no' and

robots-may-not-be-healthy/\#8de50ab1f6b7, accessed on 21 July 2020.

13 Goyal (n 6).

14 Sean Keach, 'Sex Robots Backlash as Brothel workers reveal fury over dehumanizing and dangerous droids', The Sun, 18 September 2018, available at https://www.thesun.co.uk/tech/7289486/sex-robotsprostitutes-workers-love-dolls-brothel/, accessed on 22 July 2020.

15 Becca Clarkson, 'Goodbye Brothels, Hello delivery: Vancouver's Newest Sex Doll Rental service', Vancouver Magazine, 14 January, available at https://www.vanmag.com/Goodbye-Brothels-Hello-DeliveryVancouvers-Newest-Sex-Doll-Rental-Service-is-Perfectly-Legal, accessed on 23 July 2020. 
the 'yes' model. The no model assumes consent to the activity unless an express refusal is given for it, whereas, the yes model presupposes the lack of consent unless an express approval is supplied for any particular activity. Michelle Anderson's paper Negotiating Sex introduces a third model called the negotiating model wherein, the partners communicate and consult with each other every step of the way to understand limitations and eliminate the room for speculation ${ }^{16}$.

The aspect of consent also extends to the sexbots' ability to assess the shift in the mood of the engaging partner and to immediately respond to the behavior of their partner accordingly. The difficulty in accurately understanding the cues of sexual disinterest will pose a problem for the sexbots to navigate through the entire experience and even understand non-verbal communication ${ }^{17}$. The responsibilities on the humans and the robots with regards to the intricacies of consent would expand the ethical and legal horizon of the responsibilities on the engaging parties and the possible consequences on failing to deliver on those responsibilities. Furthermore, who would be held responsible in case the robot oversteps its boundaries or fails to register the specific command?

The difficulty faced in determining the liability of the autonomous robots still remains a question. In a study conducted by the Legal Affairs Committee of the European parliament in 2016, one of the usual issues of ascribing responsibility, highlighted by the committee's report ${ }^{18}$, is that:

'Damage caused by autonomous robots might also be traced back to user error. In such instances, either strict or fault-based liability may be imposed, depending on the circumstances.'

This argument or conclusion is flawed in itself as it solely blames the victim of the act as opposed to the robot and fails to safeguard the interests of the users. This challenge should be addressed to insure against any mishap.

\section{The Boon}

The futurists and the robot enthusiasts such as David Levy have strongly advocated for sexbots by stating the advantage they pose for the disabled community by providing an opportunity for safe sexual encounters. In the UK, Human Rights Act 1998 and the Equality Act 2010, it is illegal not to support disabled people to enjoy the same pleasures as others enjoy in the privacy of their own homes ${ }^{19}$. The proponents of sexbots also

16 Michelle Anderson, 'Negotiating Sex', Working Paper, Charles Widger School of Law at Villanova University, 2005.

17 David Levy, 'Some Aspects of human consent to sex with robots', Paladyn, Journal of Behavioral Robotics, volume 11:1, 2020, available at https://www.degruyter.com/view/journals/pjbr/11/1/article-p191.xml, accessed on 24 July 2020.

18 'European Civil Rules in Robotics', Legal Affairs Committee of European Parliament, 2016.

19 'Our Sexual Future with Robots', Foundation for Responsible Robotics, Netherland, available at https:// responsible-robotics-myxf6pn3xr.netdna-ssl.com/wp-content/uploads/2017/11/FRR-ConsultationReport-Our-Sexual-Future-with-robots-.pdf. 
believe that they can help drive down the demand for sex workers, which according to $\mathrm{CNN}$ enslaves approximately 10-30 million people all across the globe. However, this theory fails to acknowledge that the conclusion is based on the assumptions that sexbots would be used in substitution and not in conjugation with sex workers ${ }^{20}$.

Many ideas have also emerged about using these robots for therapy, for otherwise depraved groups which includes treatment for erectile dysfunction and social anxiety regarding sexual encounters or they can also serve as a companion for the old. The concept of sexual therapy can further be extended to other disorders such as pedophilia and bestiality which can help eliminate these nuances of sexual crimes from the society altogether by developing the necessary mechanisms to treat the people who experience such desires in a regulated environment. Ron Arkin, a robotic professor at Georgia Institute of Technology argued that permitting the use of sexbot as prescription to treat paraphilic disorders could provide an outlet for the people and redirect them away from the other humans ${ }^{21}$. The proponents of sexbots also believe that they might also help curb the problem of global overpopulation and significantly reduce the spread of venereal diseases.

The benefits of granting legal personality to such entities include holding them accountable for their acts in the eyes of law. Thus, granting legal personality to the robots would not only protect them from exploitation but would also hold them liable for any damage caused to their human counterparts.

\section{Criticism}

The criticism towards sexbots includes their blatant objectification and extreme possibilities of dehumanization. Kathleen Richardson, professor of Ethics and the Culture of Robotics and Artificial Intelligence (AI) at De Montfort University in the UK launched a campaign against sexbots after witnessing their growing popularity, stating that they only have a commercial value and do not serve any utilitarian purpose. She believes that these bots reiterate the ago old belief of viewing women and children as objects ${ }^{22}$. They reinforce the already existing gender norms and dehumanize already vulnerable and marginalized sections of the society such as women, children and the third genders ${ }^{23}$. Richardson believes that the increased use of sexbots will dilute empathy in humans which can only be formed by experiencing mutual human relationships ${ }^{24}$.

20 Christian Wagner, 'Sexbots: The Ethical Ramifications of Social Robotics Dark Side', AI Matters, volume 3:4, 2018, available at https://sigai.acm.org/static/aimatters/3-4/AIMatters-3-4-11-Wagner.pdf.

21 European Civil Rules in Robotics (n 19).

22 Holly Ellyatt, 'Campaign launched against 'harmful' sex robots. CNBC, 15 September 2015, available at https://www.cnbc.com/2015/09/15/sex-robots-campaign.html, accessed on 26 July 2020.

23 Christopher James Headleand,William J. Teahan \& Llyr ap Cenydd, 'Sexbots: a case for artificial ethical agents', Connection Science, volume 32:2, 2019, available at https://www.tandfonline.com/doi/full/10.1080 /09540091.2019.1640185.

24 Sebastian Anthony, 'Sexbots with a "detrimental effect on society" should be banned, say researchers', Arstechnia, 15 September 2015, available at https://arstechnica.com/gadgets/2015/09/sexbots-with-adetrimental-effect-on-society-should-be-banned-say-researchers/, accessed on 27 Jul 2020. 
The misuse of this technology is not limited to the carnal sexual gratification but also the ability to customize the dolls to resemble real individuals which pose troubling facets of the invasion of privacy for some people ${ }^{25}$ and increase the ethical and moral dilemmas with respect to these entities.

Companies like True Companion which offer consumers to purchase a variant of the sexbots called Frigid Farah who does not always like to participate and engage in intimate activities which can further perpetuate the rape culture. These bots validate the behavior that feminists have been fighting against for decades. The difference in the power dynamics of the participants with respect to sexbots may increase sexual violence.

The arguments further include the dimensions under which customizations can occur would profoundly influence the users' expectations of women's bodies and promote unhealthy body images ${ }^{26}$. According to Chantal Cox-George, a doctor at St. George's University Hospitals in Great Britain, and Susan Bewley, an obstetrician at King's College London no evidence classifying the use of sexbots as healthy has been observed. Since the research was primarily based on the study of medical literature provided on the topic, no concrete conclusion about their beneficial use as claimed by the companies can be drawn. A parallelism of sexbots is being drawn to sex slaves due to the lack of consenting abilities available to them which promotes patriarchal fantasies of male domination.

\section{Conclusion}

The actual impact of sexbots cannot be predicted because of the ambiguity associated with the response of individuals with their use. However, it is expected that humans would prefer sentient beings for such encounters which have been marketed as a replacement for loneliness and the ultimate obligation to prevent their abuse falls on the engineers and the lawmakers. The critics also argue that the inherently non reciprocal relationship between the sexbot and their human counterpart will give rise to exploitative relationships with their partners as the robots are considered servile. The legislations safeguarding the interests of these humanoid dolls and to protect the humans themselves should be enacted to prevent any form of future exploitation before these bots become commercially available. It is imperative to determine their legal personality in conformity to public morality before stepping into the regulatory framework.

The concerns about the negative impact posed by them cannot be dismissed and thus more calculative and informed decisions should be made before accepting them as innocuous and as acquiescent beings manufactured, only to serve the consumer as

\footnotetext{
25 European Civil Rules in Robotics (n 19).

26 Charlotte Miller \& Indigo Miller, 'Sexbots: The Future of Fornication', Public Health Post, 15 November 2018, available at https://www.publichealthpost.org/research/sexbots-the-future-offornication $/ \#: \sim:$ text $=$ Critics $\% 20$ of $\% 20$ therapeutic $\% 20$ sexbot $\% 20$ use, actually $\% 20$ increase $\% 20$ sexual \%20violence \%20perpetration., accessed on 27 July 2020.
} 
per their demand and requirements. The fundamental dilemmas posed by sexbots regarding their design, legal and ethical compliances have to be addressed in the light of the cultural impact that they are likely to have. Robotics has percolated into the various spheres and has also proven to be beneficial for kids with autism, thus, the possibility of sexbots being used therapeutically to treat paraphilic disorders cannot be completely disregarded.

This paper aimed to highlight the future possibilities and hardships in the world where sexbots and humans co-exist, however, it is beyond the scope of the article to elaborately cover the multitudes of complexities that the commercial availability of these sexbots can pose. Highlighting the legal framework and the codes of ethics to be followed with their use should be prioritised to attain the equilibrium between safeguarding the interests of the humans and their created sentient beings. 